\title{
Validation of the 20-Item Cultural Intelligence Scale in Indian within Country Migrated Students
}

\author{
Khan Abraruzzaman Khan ${ }^{1}$, B. Hasan ${ }^{2}$
}

\section{ABSTRACT}

The objective of the present piece of work was to validation of 20 item cultural intelligence scale (CIS-20) in India within country migrated students. Following the incidental cum random sampling technique 200 North Indian engineering students within the age range of 18 to 24 years were drawn from different colleges of Warangal districts, Telangana, India to serve as participants in the present research work. The item analysis was done by corrected item-total correlation. The confirmatory factor analysis (CFA) was employed to confirm explored factors. Moreover, reliability, convergent, discriminant and concurrent validities were also examined. Conformity factor analysis (CFA) confirmed the four factor model of CIS-20. The findings indicated that CIS-20 has sufficient convergent and discriminant validity. The composite reliability was more than .700 for each of the five factors. All five factors of the CIS-20 are significantly associated with criterion measure viz. acculturative stress. It is concluded that there is sufficient empirical and statistical evidence of internal consistency and construct validity of CIS-20. The theoretical and practical issues have been discussed.

Keywords: Cultural Intelligence, Acculturative Stress

According to ministry of cultural Affairs government of India, India has Seven cultural zones. All cultural zones are distinct from each other. Every year several students migrate for study in other cultural zone sates. When students migrate from one cultural zone sates to another cultural zone sates, during the transition and early settlement period they may face unique adjustment related issues. Earlier studies suggested that cultural intelligence was significant associated with psychological (psychological well-being) and socio-cultural (instructional, work, etc.) adjustment in the diverse cultural setup (Ang, et al., 2007). Those people having higher cultural intelligence are more effective at making decisions about intercultural situations (Ang, et al., 2007). Cultural intelligence was a significantly stronger predictor of leadership effectiveness in cross border contexts among swiss military leaders (Rockstuhl, Ang, Ng, Van Dyne, \& Lievens, 2009).

\footnotetext{
${ }^{1}$ Psychiatric Department, All India Institute of Medical Science, Raipur, India

${ }^{2}$ Psychometrics Laboratory, School of Studies in Psychology, Pt. Ravishankar Shukla University, Raipur, India *Responding Author (c) 2016 I KA Khan, B Hasan; licensee IJIP. This is an Open Access Research distributed under the terms of the Creative Commons Attribution License (http://creativecommons.org/licenses/by/2.0), which permits unrestricted use, distribution, and reproduction in any Medium, provided the original work is properly cited.
} 
Cultural intelligence associated with the development of social network, language (host cultural language) fluency among international students (Fehr \& Kuo, 2008). Cultural intelligence associated with higher centrality in a friendship network for social support among international engineers (Gjertsen, Torp, Koh, \& Tan, 2010). Cultural intelligence is positively associated with acculturation experiences (Shannon \& Begley, 2008; Takeuchi, Tesluk, Yun, \& lepaks’s, 2005; Crowne, 2008; Tay, Westman \& Chia, 2008). On the other hand, among professional acculturation experience was a significant predictor of motivational CQ (Crowne, 2008). But Tarique and Takeuchi (2008) noted that acculturation experience was significant predictors of all four aspects of cultural intelligence viz. [strategy (meta-cognition), knowledge (cognition), motivation (drive) and behavior (action)]. Length of travel is positively associated with metacognition CQ and cognitive CQ (Tarique \& Takeuchi, 2008).

Cultural intelligence (CQ) indicated that person better ability to adjustment and adaptation of various cultural systems (Ang, Van Dyne, \& Koh, 2006). Ang, Van Dyne, and Koh, (2006) reported that, cultural intelligence is integration of strategy (meta-cognition), knowledge (cognition), motivation (drive) and behavior (action).

Strategy is associated with one's sense of diverse cultural system. Its include planning- planning of purpose and duration of migration before encounter, awareness- awareness mental process and behavioral pattern of host culture members; awareness of cross-cultural situation, and checkingevaluations of mental map and checking assumption (Van Dyne, Ang, Ng, Rockstuhl, Tan, \& Koh, 2012).

Knowledge is associated with one's knowledge about the host culture (Ang, Van Dyne, \& Koh, 2006). It's composed: business -information about the economic and legal system at host culture, interpersonal- knowledge of values, norms, practices and religious beliefs at host culture, and socio-linguistics- knowledge of linguistic rules and verbal Vs non-verbal communication rules (Van Dyne, Ang, Ng, Rockstuhl, Tan, \& Koh, 2012).

Motivation is linked with one's ability to direct attention and energy toward learning about functioning in cross-cultural situations (Ang, Van Dyne, \& Tan, 2011). Its integration of: intrinsic interest- enjoyment from acculturation experience, extrinsic interest- some benefits from acculturation experience, and self-efficacy- confidence with acculturation experience (Livermore, 2010).

A behavior aspect of cultural intelligence is one's ability to adoption of verbal and nonverbal behavior at host cultural; exhibit the suitable verbal and non-verbal behaviors at host culture (Van Dyne, Ang, Ng, Rockstuhl, Tan, \& Koh, 2012). Livermore (2010) noted behavioral CQ is integration of: modification of non-verbal (i.e. gestures, facial expressions etc.) and Verbal (i.e. pronunciation, tone, pitch etc.). 
Several studies validated 20- item cultural intelligence scale in western context (S. Ang, 2006; Soon Ang et al., 2007; Dyne, Ang, \& Koh, 2008; Johnson, 2014; Khodadady \& Ghahari, 2011; Mahembe \& Engelbrecht, 2014) But validation study of 20- item cultural intelligence scale in Indian context has not yet been ascertained. Thus, the objective of the present study was to validation of 20- item cultural intelligence scale (CIS-20) in Indian context.

\section{METHOD}

\section{Participants}

North Indian engineering students is target population in the present research. North Indian engineering students are students who migrated to Warangal district, (Telangana) from north Indian states for the purpose of the study in engineering faculty. Participants from north Indian cultural zone and north central India cultural zone states are included. Further, postgraduate, research engineering students are excluded. No sampling frames are available regarding north Indian engineering students at Warangal district. Therefore, 200 north Indian engineering students were drawn from different engineering college at Warangal district, by incidental cum random sampling technique. Students were male 151 (75.5\%) and female 49 (24.5\%) respectively in present study. Age ranged of participants from 17 to 25 years [17-19 (33.0\%), 20$22(38.0 \%)$ and $23-25(29.0 \%)]$. Acculturation experience ranged of participants from $<1$ year to $>4$ years. Total number of participants with acculturation experiences of $<1$ year had 44 (22.0\%), 1 to 2 years had 57 (28.5\%), 2 to 3 years had 51 (25.5\%), 3 to 4 years had 43 (21.5\%) and $>4$ years had 5 (2.5\%). The percentages of participants belonging to nuclear and joint families were $70.0 \%$ and $30.0 \%$ respectively.

Percentage value of participants concerning to semester $2^{\text {nd }}(23 \%), 4^{\text {th }}(29.0 \%), 6^{\text {th }}(25.0 \%)$ and $8^{\text {th }}(23.0 \%)$. Total number of participants living with accommodation, private and hostel were 60 (30.0\%) and $120(70.0 \%)$ respectively. The majority of participants belong to urban area (49.0\%). The percentages of participants concerning to single and shared type of accommodation were $50.0 \%$ and $49.0 \%$ respectively. The majority of participants 142 (71\%) reported they spoke English in college.

Percentage value of participants concerning to total family income (per month) 10,000-15,000 (2.0\%), 15,001-20,000 (3.0\%), 20,001-25,000 (10.0\%), 25,001-30,000 (41.0\%) and 30,000> (44.0\%). The percentage value of participants pertaining to mothers education- illiterate 4 (2.0\%), preprimary 10 (5.0\%), primary 4 (2.0\%), high school 28 (14.0\%), higher secondary 64 (32.0\%) and gradation 90 (45.0\%). The majority of participants 70 (35\%) reported their father occupation is govt. employee.

\section{Procedure}

Prior to initiation of the study, all participants gave their informed and written consent. The study obtained ethics approval of the institutional ethics committee for human research of the Pt. 
Ravishankar Shukla University, Raipur, India. Introductory interview with the participants was made at different colleges at Warangal district. They were aware about the objective of the research. Introductory interview, each participant was also illustrated the temperament of the research and the participants were illustrated about the privacy regarding acquaintance collected from them. They were urged to complete the questionnaire as per the instructions and after completion they returned the test and were acknowledged for their collaboration.

\section{Validation of CIS-20}

Item analysis was carried out by corrected item-total correlation. In the present work $\geq .600$ item-total correlation values was the criteria for item inclusion as recommend by Hair, Black, Babin, and Anderson, (2010). CFA was employed to confirm four factor model of CIS-20. The fitness of model with the data was evaluated with guideline recommended by Hooper, Coughlan, and Mullen, (2008). Reliability, convergent and discriminant validities were evaluated with guideline recommend by Hair, Black, Babin, and Anderson, (2010). Concurrent validity analyses were carried out. Some studies indicated that, cultural intelligence negatively associated with acculturative stress (Ayoob, Wani, Ahmad, Jan \& Dar, 2015; Cuadrado, Tabernero, \& Briones, 2014; Khan, 2015) on the basis this concrete evidence hypothesis; CIS-20 would be negatively associated with the 16 item acculturative stress scale (Khan, 2015).

All 200 cases were included for statistical analyses. SPSS version 21.0, AMOS version 21 and Stats tool package-KolobKreations were used. In the present research all statistical hypotheses were evaluated at $\mathrm{p}<0.05$.

\section{RESULTS}

The corrected item-total correlation coefficient for each of the items of CIS-20 was greater than .600 (Table-1). Thus, all items were retained for next procedure. CFA was employed to check consistencies in four factor of CIS-20 with by AMOS 22.0 software. Table-2 indicated that chi square value is not statistically significant ( $\chi 2=94.19$, $p$-value $>5 \%$ ), RMSEA is less than .070, GFI is higher than .950, RMR is less than .050, NFI is higher than .950 and CFI is higher than .950. These findings indicated that CIS-20 represented a good fitting to our data (Hooper, Coughlan, \& Mullen, 2008). Further, figure-1 indicated that there is a significant standardized regression weight of all the items on their respective factors and specifically, the values for $\beta$ ranged from .760 to .910 for meta-cognition CQ, .780 to .890 for cognition CQ, .820 to .950 for motivation CQ, and .848 to .963 for behavior CQ. However, relationships among the factors are insignificant, which confirm that all the four factors are empirically distinct from each other.

Standardized regression weights of CIS-20 range from .760 to .960 (figure-1). Table-3 indicated that, average variance extracted (AVE) values of all constructs are greater than .500. This is evidences for good convergent validity of CIS-20 (Hair, Black, Babin, \& Anderson, 2010). AVE values of all constructs are greater than MSV and ASV. Further, square root of AVE value is greater than inter-construct correlations regarding all constructs. These are evidences for good 
discriminant validity of CIS-20 (Hair, Black, Babin, \& Anderson, 2010). Composite reliability (CR) values of all factors are greater than .700. This is evidences for good reliability of CIS-20 (Hair, Black, Babin, \& Anderson, 2010).

All four factors of the CIS-20 are significantly and negatively correlated with 16 items acculturative stress scale (table-4). These evidence are suggests good concurrent validity of the CIS-20.

\section{DISCUSSION}

The objective of the present research work is to validation of 20- item cultural intelligence scale (CIS-20) in Indian context. CIS-20 was validated following psychometric procedures for scale validation as recommend by Nunnally and Bernstein (1994). In the present sample the corrected item-total correlation of this measure are greater than .600 (Hair, Black, Babin, \& Anderson, 2010). CFA confirmed the four factor of cultural intelligence. Moreover, values of the absolute and comparative fit indices indicated and supported a good model fit to the data (Hooper, Coughlan, \& Mullen, 2008). Our observations are comparable with the findings reported earlier (S. Ang, 2006; Soon Ang et al., 2007; Dyne, Ang, \& Koh, 2008; Johnson, 2014; Khodadady \& Ghahari, 2011; Mahembe \& Engelbrecht, 2014).

Further, results indicate that CIS-20 has good convergent and discriminant validities. Resultant higher values of AVE of each factor with regard to its correlation with other factors confirmed the convergent validity of CIS-20. Similarly, discriminant validity was established on the basis of maximum shared variance (MSV $<\mathrm{AVE}$ ), average shared variance (ASV $<\mathrm{AVE}$ ), and square root of AVE greater than inter-factor correlations. Our results on discriminant validity are in agreement with the criteria suggested by (Hair, Black, Babin, \& Anderson, 2010). Furthermore, the estimated values for reliability computed as composite reliability of each of the factors of CIS-20 were more than .700 (Hair, Black, Babin, \& Anderson, 2010). This implied that the CIS20 has good reliability. All four factors of the CIS-20 are significantly associated with criterion measures. The correlation coefficient values were also high. These are concrete evidences for good concurrent validity of the CIS-20.

\section{CONCLUSION}

It is concluded that there is sufficient empirical and statistical evidence of CIS-20 in India context. These findings strengthen our assumption that the CIS-20 is a reliable valid scale and could be used to assess level of cultural intelligence in within country migrated student. Dimensions of CIS-20 are capable of measuring assumptions of the cultural intelligence in within country migrated student independently and fairly accurately. 


\section{REFERENCE}

Ang, S. (2006). Personality Correlates of the Four-Factor Model of Cultural Intelligence. Group \& Organization Management, 31(1), 100-123. doi:10.1177/1059601105275267

Ang, S., Van Dyne, L., \& Koh, C. S. K. (2006). Personality correlates of the four-factor model of cultural intelligence. Group and Organization Management, 31, 100-123.

Ang, S., Van Dyne, L., \& Tan, M. L. (2011). Cultural intelligence. In R. J. Sternberg \& B. S. Kaufman (Eds.), Cambridge Handbook of Intelligence (pp. 582-602). Cambridge: Cambridge University Press.

Ang, S., Van Dyne, L., Koh, C. K. S., Ng, K. Y., Templer, K. J., Tay, C., \& Chandrasekar, N. A. (2007). The measurement of cultural intelligence: Effects on cultural judgment and decision making, cultural adaptation, and task performance. Management and Organization Review, 3, 335-371.

Ang, S., Van Dyne, L., Koh, C., Ng, K., Templer, K., Tay, C., \& Chandrasekar, N. (2007). Cultural Intelligence: Its Measurement and Effects on Cultural Judgment and Decision Making, Cultural Adaptation, and Task Performance. Management and Organization Review, 3(3), 335-371. doi:10.1111/j.1740-8784.2007.00082.x

Crowne, K. (2008). What leads to cultural intelligence? Business Horizons, 51, 391-399. doi:10.1016/j.bushor.2008.03.010.

Cuadrado, E., Tabernero, C., \& Briones, E. (2014). Dispositional and Psychosocial Variables as Longitudinal Predictors of Acculturative Stress. Applied Psychology, 63(3), 441-479. doi:10.1111/j.1464-0597.2012.00531.x

Dyne, L. Van, Ang, S., \& Koh, C. (2008). Development and Validation of the CQS. Handbook of Cultural Intelligence: Theory, Measurement, and Applications. Retrieved fromhttp://books.google.com/books?hl=en\&lr=\&id=FSTzFksL0IkC\&pgis=1 1nhttp://boo ks.google.com/books?hl=en\&amp;lr=\&amp;id=FSTzFksL0IkC\&amp;oi=fnd\&amp;pg=P R5\&amp;dq=Handbook+of+cultural+intelligence:+theory,+measurement,+and+applicati ons\&amp;ots=39NMOaElvy\&amp;sig=brbskaff4yWmmhF3khmYIFca2jw $\backslash n h t t p: / / c u l t u r$ alq.com/docs/Van Dyne_Ang_Koh Handbook Ch 2 CQS Scale.pdf

Fehr, R., \& Kuo, E. (2008, August). The impact of cultural intelligence in multicultural social networks. Paper presented at the 23rd Annual Conference of the Society for Industrial and Organizational Psychology, San Francisco, CA.

Gjertsen, T., Torp, A. M., Koh, C. K., \& Tan, M. L. (2010, August). The impact of cultural intelligence on homophily in intracrrganizational multinational networks. Paper presented at the annual meeting of the Academy of Management, Montreal, Canada.

Hair, J. F., Black, W. C., Balin, B. j., \& Anderson, R. E. (2010). Multivariate data analysis: Maxwell Macmillan International Editions.

Hooper, D., Coughlan, J., \& Mullen, M. (2008). Structural Equation Modelling : Guidelines for Determining Model Fit. Electronic Journal of Business Research Methods, 6(1), 53-60.

Johnson, R. B., \& Buko, S. (2014). Cultural Intelligence Scale (CQS): Testing Cross-cultural Transferability of CQS in Ukraine. Studies of Changing Societies, 2013(4), 52-67. doi:10.2478/scs-2014-0160 
Khan, K. A. (2015). Psychological Predictors of Acculturative Stress among North Indian Engineering Students (Unpublished PhD thesis). Pt. Ravishankar Shukla University, Raipur, India.

Khodadady, E., \& Ghahari, S. (2011). Validation of the Persian Cultural Intelligence Scale and Exploring Its Relationship with Gender, Education, Travelling Abroad and Place of Living. Global Journal of Human Social Science, 11(7), 64-76.

Mahembe, B., \& Engelbrecht, A. S. (2014). A preliminary study to assess the construct validity of a cultural intelligence measure on a South African sample. SA Journal of Human Resource Management, 12(1), 1-8. doi:10.4102/sajhrm.v12i1.558

Nunnally J. C., Bernstein I. H. (1994) Psychometric theory, 3rd Edn. McGraw-Hill, New York.

Rockstuhl, T., Ang, S., Ng, K.-Y., Van Dyne, L, \& Lievens, F. (2009, August). Cultural intelligence and leadership emergence in multicultural teams. Paper presented at the annual meeting of the Academy of Management, Chicago.

Shannon, L. M., \& Begley, T. M. (2008). Antecedents of the four-factor model of cultural intelligence. In S. Ang \& L. Van Dyne (Eds.), Handbook of cultural intelligence: Theory, measurement, and applications (pp. 41-55). New York, NY: Sharpe.

Takeuchi, R., Tesluk, P. E., Yun, S., \& Lepak, D. P. (2005). An integrative view of international experience. Academy of Management Journal, 48, 85-100. doi:10.5465/AMJ.2005.15993 $/ 43$.

Tarique, I., \& Takeuchi, R. (2008). Developing cultural intelligence: The roles of international nonwork experiences. In S. Ang \& L. Van Dyne (Eds.), Handbook of cultural intelligence: Theory, measurement, and applications (pp. 56-70). New York, NY: Sharpe.

Tay, C., Westman, M., \& Chia, A. (2008). Antecedents and consequences of cultural intelligence among short-term business travelers. In S. Ang (Sr. L. Van Dyne (Eds.), Handbook of cultural intelligence: Theory, measurement, and applications (pp. 126-144). New York, NY: Sharpe.

Van Dyne, L., Ang, S., Ng, K. Y., Rockstuhl, T., Tan, M. L., \& Koh, C. (2012) Sub-Dimensions of the Four Factor Model of Cultural Intelligence: Expanding the Conceptualization and Measurement of Cultural Intelligence. Social and Personality Psychology Compass, 6(4), 295-313. doi:10.1111/j.1751-9004.2012.00429.x 
Validation of the 20-Item Cultural Intelligence Scale in Indian within Country Migrated Students

Table- 1, Corrected item-total correlation for CIS-20

\begin{tabular}{|c|c|c|c|c|}
\hline Factors & $\begin{array}{c}\text { Item } \\
\text { No. }\end{array}$ & Item description & $\begin{array}{l}\text { Corrected } \\
\text { item-total } \\
\text { correlation }\end{array}$ & Remark \\
\hline \multirow{4}{*}{$\begin{array}{l}\text { Meta } \\
\text { Cognition }\end{array}$} & 1 & $\begin{array}{l}\text { I am conscious of the cultural knowledge I use } \\
\text { when interacting with people with different } \\
\text { cultural backgrounds. }\end{array}$ & .812 & Retained \\
\hline & 2 & $\begin{array}{l}\text { I adjust my culture knowledge as I interact with } \\
\text { people from a culture that is unfamiliar to me. }\end{array}$ & .892 & Retained \\
\hline & 3 & $\begin{array}{l}\text { I am conscious of the culture knowledge I apply } \\
\text { to cross-cultural interactions. }\end{array}$ & .790 & Retained \\
\hline & 4 & $\begin{array}{l}\text { I check the accuracy of my cultural knowledge as } \\
\text { I interact with people from different cultures. }\end{array}$ & .751 & Retained \\
\hline \multirow{6}{*}{ Cognition } & 5 & $\begin{array}{l}\text { I know the legal and economics systems of other } \\
\text { cultures. }\end{array}$ & .790 & Retained \\
\hline & 6 & $\begin{array}{l}\text { I know the rules (viz. vocabulary, grammar) of } \\
\text { other languages. }\end{array}$ & .824 & Retained \\
\hline & 7 & $\begin{array}{l}\text { I know the cultural values and religious belief of } \\
\text { other cultures. }\end{array}$ & .718 & Retained \\
\hline & 8 & I know the marriage systems of other cultures. & .801 & Retained \\
\hline & 9 & I know the arts and crafts of other cultures. & .912 & Retained \\
\hline & 10 & $\begin{array}{l}\text { I know the rules for expressing non-verbal } \\
\text { behaviors in other cultures. }\end{array}$ & .831 & Retained \\
\hline \multirow{5}{*}{ Motivation } & 11 & $\begin{array}{l}\text { I enjoy interacting with people from different } \\
\text { cultures. }\end{array}$ & .790 & Retained \\
\hline & 12 & $\begin{array}{l}\text { I am confident that I can socialize with locals in a } \\
\text { culture that is unfamiliar to me. }\end{array}$ & .824 & Retained \\
\hline & 13 & $\begin{array}{l}\text { I am sure I can deal with the stresses of adjusting } \\
\text { to a culture that is new to me. }\end{array}$ & 699 & Retained \\
\hline & 14 & $\begin{array}{l}\text { I enjoy living in cultures that are unfamiliar to } \\
\text { me. }\end{array}$ & .801 & Retained \\
\hline & 15 & $\begin{array}{l}\text { I am confident that I can get accustomed to me } \\
\text { shopping conditions in a different culture. }\end{array}$ & .851 & Retained \\
\hline \multirow{5}{*}{ Behavior } & 16 & $\begin{array}{l}\text { I change my verbal behavior (viz. accent, tone) } \\
\text { when a cross-cultural interaction requires it. }\end{array}$ & .723 & Retained \\
\hline & 17 & $\begin{array}{l}\text { I use pause and silence differently to suit different } \\
\text { cross-cultural situations. }\end{array}$ & .750 & Retained \\
\hline & 18 & $\begin{array}{l}\text { I vary the rate of my speaking when a cross- } \\
\text { cultural situation required it. }\end{array}$ & .832 & Retained \\
\hline & 19 & $\begin{array}{l}\text { I change my non-verbal behavior when a cross- } \\
\text { cultural situation required it. }\end{array}$ & .760 & Retained \\
\hline & 20 & $\begin{array}{l}\text { I alter my facial expressions when a cross-cultural } \\
\text { interaction requires it. }\end{array}$ & .871 & Retained \\
\hline
\end{tabular}


Validation of the 20-Item Cultural Intelligence Scale in Indian within Country Migrated Students

Table-2, Model fit indicates for ASS-16

\begin{tabular}{|l|c|c|}
\hline \multicolumn{1}{|c|}{ Indicates } & Satisfactory levels & Obtained value \\
\hline Absolute indicates & $<3.0$ & $94.19 / 71=1.32$ \\
\hline$\chi^{2} /$ df & $<.070$ & .021 \\
\hline RMSEA & $>.950$ & .985 \\
\hline GFI & $<.050$ & .018 \\
\hline RMR & & .981 \\
\hline Comparative fit indices & $>.950$ & .979 \\
\hline NFI & $>.950$ & \\
\hline CFI & & \\
\hline Decision- Good fitting model & & \\
\hline
\end{tabular}

Table-3, Convergent, Discriminant validities, composite reliabilities evaluation and interconstruct correlations for CIS-20

\begin{tabular}{|c|c|c|c|c|c|c|c|c|}
\hline & CR & AVE & MSV & ASV & Motivation & Cognition & Behavior & $\begin{array}{c}\text { Meta } \\
\text { Cognition }\end{array}$ \\
\hline Motivation & .945 & .774 & .026 & .013 &. $\mathbf{8 8 0}$ & & & \\
\hline Cognition & .924 & .710 & .014 & .008 & .060 & .842 & & \\
\hline Behavior & .952 & .801 & .026 & .013 & .160 & .120 &. $\mathbf{8 9 5}$ & \\
\hline $\begin{array}{c}\text { Meta } \\
\text { Cognition }\end{array}$ & .919 & .694 & .010 & .006 & .100 & .080 & .020 & $\mathbf{. 8 3 3}$ \\
\hline
\end{tabular}

Table-4, Correlation with all five factors of the CIS-20 and criterion measure

\begin{tabular}{|l|c|}
\hline & $\mathbf{1 6}$ item acculturative stress scale \\
\hline Meta Cognition & $-.710^{* *}$ \\
\hline Cognition & $-.785^{* *}$ \\
\hline Motivation & $-.712^{* *}$ \\
\hline Behavior & $-.812^{* *}$ \\
\hline
\end{tabular}

$$
* * \mathrm{p}<.01
$$




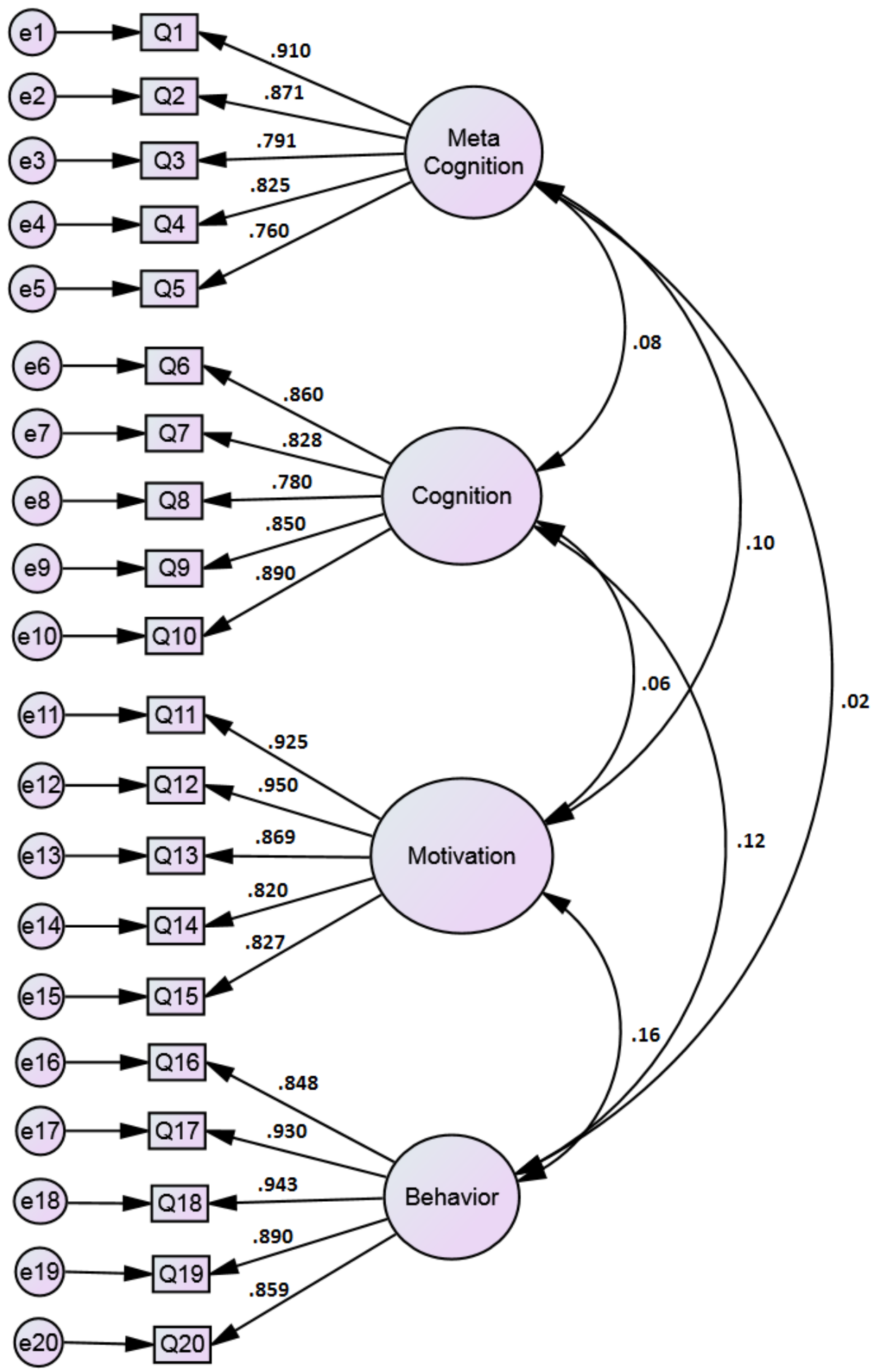

Figure- 1 Factorial validity of CIS-20 